\title{
Awareness and behavioral problems in dementia patients: a prospective study
}

Citation for published version (APA):

Aalten, P., van Valen, E., de Vugt, M. E., Lousberg, R., Jolles, J., \& Verhey, F. R. J. (2006). Awareness and behavioral problems in dementia patients: a prospective study. International Psychogeriatrics, 18(1), 3-17. https://doi.org/10.1017/S1041610205002772

Document status and date:

Published: 01/01/2006

DOI:

10.1017/S1041610205002772

Document Version:

Publisher's PDF, also known as Version of record

\section{Please check the document version of this publication:}

- A submitted manuscript is the version of the article upon submission and before peer-review. There can be important differences between the submitted version and the official published version of record.

People interested in the research are advised to contact the author for the final version of the publication, or visit the DOI to the publisher's website.

- The final author version and the galley proof are versions of the publication after peer review.

- The final published version features the final layout of the paper including the volume, issue and page numbers.

Link to publication

\footnotetext{
General rights rights.

- You may freely distribute the URL identifying the publication in the public portal. please follow below link for the End User Agreement:

www.umlib.nl/taverne-license

Take down policy

If you believe that this document breaches copyright please contact us at:

repository@maastrichtuniversity.nl

providing details and we will investigate your claim.
}

Copyright and moral rights for the publications made accessible in the public portal are retained by the authors and/or other copyright owners and it is a condition of accessing publications that users recognise and abide by the legal requirements associated with these

- Users may download and print one copy of any publication from the public portal for the purpose of private study or research.

- You may not further distribute the material or use it for any profit-making activity or commercial gain

If the publication is distributed under the terms of Article $25 \mathrm{fa}$ of the Dutch Copyright Act, indicated by the "Taverne" license above, 


\title{
2005 IPA RESEARCH AWARDS FIRST-PRIZE WINNER Awareness and behavioral problems in dementia patients: a prospective study
}

\author{
Pauline Aalten, Evelien van Valen, Marjolein E. de Vugt, \\ Richel Lousberg, Jelle Jolles and Frans R. J. Verhey \\ Dopartment of Psychiaty and Nelropsychology, Brain and Behavior Institute, University of Maasticht, \\ Maustricht, the Netherlands
}

ABSTRACT

Background: The results of studies of the association between awareness and clinical correlates in patients with dementia are inconclusive. The aims of this study were to investigate whether awareness changed during the course of dementia and to determine whether awareness was associated with certain behavioral symptoms. Specifically, it was hypothesized that relatively intact awareness was related to affective disorders.

Methods: One hundred and ninety-nine patients with dementia were included in a prospective 18-month follow-up study. Behavioral problems were assessed with the Neuropsychiatric Inventory and the Cornell Scale for Depression in Dementia. Awareness was assessed by means of the Guidelines for the Rating of Awareness Deficits.

Results: Cross-sectional analyses showed awareness to be positively associated with age, gender, education and socioeconomic status, and negatively associated with psychosis, apathy, and overall behavioral disorders at baseline. After 1 year, a higher level of awareness was related to depression and anxiety. The level of awareness at baseline also predicted depression and anxiety after 1 year. Awareness decreased during the study.

Conclusions: A higher level of awareness is associated with subsyndromal depression and anxiety, whereas lack of awareness is associated with psychosis and apathy. The level of awareness decreases as dementia progresses. Clinicians should be more alert to changes in awareness in patients with dementia because psychosocial support might help to prevent the development of affective symptoms.

Key words: neuropsychiatric symptoms, Alzheimer's disease, awareness, Neuropsychiatric Inventory, depression, anxiety, apathy

Correspondence should be addresscd $w$ : Dr. P. Aalten, Department of Psychiatry and Neuropsychology, University Hospital of Manstricht, PO Box 5800, 6202 AZ Maastricht, the Netherlands. Phone: +31433884104 ; Fax; +31433875444 Email: p.aalten@inp, unimaas.nl. Received 2 Aug 2005; accepted 3 Aug 2005. First published online 03 Jan 2006. 


\section{P. Aalten et al.}

In recent years there has been a growing interest in the concept of awareness in people with dementia. Several terms have been proposed to describe this phenomenon; however, complexities around the concept and relationships of awareness or insight still exist (Aalten et al., 2005; Clare, 2004b; Markova et al., 2005). In the present study, the term "awareness" is used as synonymous with awareness of memory difficulty and its impact.

Considerable attention has been paid to the role of awareness in dementia and in particular its associations with cognitive function. Less is known about relationships between awareness and behavioral and psychological symptoms of dementia (BPSD). Some studies (Burke et al., 1998; Feher et al., 1991; Harwood et al., 2000; Migliorelli et al., 1995; Seltzer et al., 1995; Sevush and Leve, 1993; Smith et al., 2000; Starkstein et al., 1996; 1997), but not all (Arkin and Mahendra, 2001; Cummings et al., 1995; DeBettignies et al., 1990; Derouesné et al., 1999; Lopez et al., 1994; Michon et al., 1994; Ott et al., 1996a; Reed et al., 1993; Verhey et al., 1993; Zanetti et al., 1999), show intact awareness to be associated with depressive symptoms and with anxiety (Derouesné et al., 1999; Harwood et al., 2000; Verhey et al., 1993), although the latter association was not found by Seltzer et al. (1995). There is evidence that decreased awareness may be associated with apathy (Derouesné et al., 1999; Robert et al., 2002; Starkstein et al., 1996; 2001), agitation, irritability (Harwood et al., 2000; Seltzer et al., 1995; Starkstein et al., 1995) and psychosis (Mangone et al., 1991; Migliorelli et al., 1995; Starkstein et al., 1996; 1997).

Moreover, some studies have shown that awareness decreases as dementia worsens (Derouesné et al., 1999; Feher et al., 1991; Harwood et al., 2000; Lopez et al., 1994; Mangone et al., 1991; Migliorelli et al., 1995; Seltzer et al., 1995; Sevush, 1999; Sevush and Leve, 1993; Starkstein et al., 1996; 1997; Vasterling et al., 1995; Verhey et al., 1993; Zanetti et al., 1999), whereas others found no such association (Arkin and Mahendra, 2001; Auchus et al., 1994; Kotler-Cope and Camp, 1995; Michon et al., 1994; Reed et al., 1993; Vasterling et al., 1997). These inconsistencies between studies could be due to the use of small samples of patients, different operationalizations of awareness, and cross-sectional data. There is a need for prospective longitudinal studies of larger cohorts. Although Starkstein et al. (1997), Vasterling et al. (1997), Derouesné et al. (1999), Sevush (1999) and Arkin and Mahendra (2001) performed longitudinal studies of the course of awareness in patients with dementia, their studies included relatively smail samples of patients and the period of follow-up was limited.

In the present study, we prospectively studied 199 patients with dementia for 18 months. Our primary aim was to examine whether awareness is a predictor of behavioral problems, whether specific types of behavior are associated with level of awareness, and how awareness changes during the course of dementia. 
We specifically examined the hypothesis that intact awareness is associated with affective disorders, and especially depression.

\section{Methods}

\section{Patients}

The present study was part of the Maastricht Study of Behavior in Dementia (MAASBED), a study that focuses on the course and risk factors of BPSD. MAASBED is a 2-year prospective study of 199 patients with dementia, who are seen at 6 -month intervals. Patients were subsequently referred to the Maastricht Memory Clinic of the University Hospital Maastricht, or the geriatric division of the Regional Institute for Community Mental Health Care (RIAGG), Maastricht.

Patients were included when they met the DSM-IV criteria for dementia (American Psychiatric Association, 1994) and if there was a reliable informant. Of these, 146 patients met the NINCDS-ADRDA (McKhann et al., 1984) (possible, probable) criteria for Alzheimer type dementia, 32 patients the NINCDSAIREN criteria for vascular dementia (Román et al., 1993), two dementia with Lewy bodies (DLB) (McKeith et al., 1996), and 19 dementia due to multiple etiologies.

Patients were excluded if they were living in a nursing home at the start of the study. Written consent was given by the caregiver and, when possible, by the patient. The Medical Ethics Committee of the University Hospital Maastricht approved this study.

For the present study, data were available for baseline, and 6-, 12- and 18-month follow-up evaluations. After 6 months, 30 patients refused participation and 12 patients had died; after 1 year, nine patients refused participation and 11 patients had died; after 18 months, seven refused participation and 13 patients had died. Complete follow-up data were thus available for 117 patients $(58.8 \%)$. The 82 patients who did not complete the entire study did not differ from those who attended all follow-up evaluations with regard to age, sex, severity of dementia, severity of behavioral problems, and awareness score at study onset.

\section{Measurements}

\section{Behavioral problems}

Behavioral problems were assessed with the Neuropsychiatric Inventory (NPI) (Cummings et al., 1994) and the Cornell Scale for Depression in Dementia (CSDD) (Alexopoulos et al., 1988). The NPI is a reliable, informant-based 
rating scale developed to assess psychopathology in patients with dementia. The current version (Cummings, 1997) evaluates 12 neuropsychiatric symptoms that are commonly observed in dementia. The severity and frequency of each symptom are scored on the basis of structured questions administered to the patient's caregiver. The score for each symptom is obtained by multiplying severity $(1-3)$ by frequency $(1-4)$. The summed symptom scores give the total NPI score. The validity and reliability of the NPI (Cummings and McPherson, 2001) and its Dutch version (Kat et al., 2002) have been established.

For this study, NPI items were clustered based on a previous principal component analysis study to minimize the number of variables (Aalten et al., 2003). This resulted in three factors: (1) a "mood/apathy" factor, including depression, apathy, night-time behavior disturbances and eating abnormalities (four items, Cronbach's $\alpha=0.63$ ); (2) a "hyperactivity factor," including the symptoms agitation, euphoria, irritability, disinhibition and aberrant motor behavior (five items, $\alpha=0.73$ ); and (3) a "psychosis factor," including hallucinations and delusions (two items, $\alpha=0.72$ ). Anxiety was regarded as a separate symptom. The total score for each subsyndrome was calculated by summing the NPI item scores for each factor.

In addition, the CSDD (Alexopoulos et al., 1988) was used to measure mood disturbances and was administered to the caregivers and patients. The CSDD is a 19-item clinician-rated instrument with item scores ranging from 0 (absent) to 2 (severe), with a maximum score of 38 points.

\section{Awareness}

Awareness was assessed by means of the Guidelines for the Rating of Awareness Deficits (GRAD) Verhey et al., 1993; Zanetti et al., 1999). The GRAD is a semistructured interview in which the degree of awareness is assessed by comparing the patient's and the caregiver's information about the patient's history. Impaired awareness is defined as the absence of knowledge or recognition of cognitive deficits and its impact. It is rated on a four-point scale, ranging from 4 (intact), 3 (mildly disturbed), 2 (moderately disturbed) to 1 (absent).

\section{Procedure}

In addition to general information on demographics, disease duration (years), level of education, socioeconomic status (SES) and medical history gathered from the primary caregivers, trained research assistants administered cognitive tests to the patients. The Mini-mental State Examination (MMSE) (Folstein et al., 1975) was administered as a measure of cognitive decline and the Global Deterioration Scale (GDS) as a measure of severity of dementia (Reisberg et al., 1982). 


\section{Statistical analyses}

Statistical analyses were performed with the Statistical Package for Social Sciences, version 10. To determine whether awareness was related to behavioral disorders during the 18-month follow-up, logistic regression analyses were performed on the three subsyndromes of the NPI and the CSDD, with awareness as the independent variable. The subsyndromes were dichotomized by median split. Separate analyses were also performed for the symptoms anxiety, depression and apathy, as measured by the NPI.

Cross-sectional analyses were performed for each assessment time, correcting for age, sex, SES and severity of dementia (GDS). Longitudinal analyses were performed looking at baseline GRAD as predictor of the subsyndromes and separate symptoms. Age, sex, SES and GDS were again included as covariates, as were the baseline scores for the subsyndromes.

To test differences in descriptive sample characteristics between the four awareness groups, one-way analysis of variance (ANOVA), $\chi^{2}$-tests and KruskalWallis tests were used as appropriate. To determine whether awareness decreased with time, ANOVA with repeated measures with time (baseline, 6-, 12- and 18 months) as the within-subject factor was computed. All significance tests were performed at a two-tailed $\alpha$ level of 0.05 .

\section{Results}

\section{Patient characteristics and relationships with awareness}

At baseline, 83 men (41.7\%) and 116 women (58.3\%) were included in the study (see Table 1 ). The mean age was $76.4 \pm 8.0$ years (range $53-96$ years). Most patients had a relatively low education and SES. The mean disease duration was $3.0 \pm 2.2$ years. The average MMSE score was $18.1 \pm 4.7$ at baseline and declined significantly at each follow-up, to reach $16.0 \pm 6.1$ after 18 months. The GDS score increased significantly during follow-up, indicating that severity of dementia increased over time.

A series of one-way ANOVAS found significant effects of age on awareness at baseline $(F(3,198)=2.73, p=0.05)$ and 1 year $(F(3,143)=3.14, p=0.03)$, showing younger age to be associated with intact awareness. Intact awareness was also associated with lower GDS $(p<0.001)$ and higher MMSE scores ( $p=0.01$ or $p<0.001$ at 6 months) at all assessments, indicating that awareness is negatively associated with severity of dementia. There were also sex differences, with men having a more intact insight at baseline $\left(\chi^{2}=25.5\right.$, d.f. $\left.=3, p<0.001\right)$ and at 1 year $\left(\chi^{2}=8.06\right.$, d.f. $\left.=3, p=0.05\right)$. Kruskal-Wallis tests revealed positive associations between education and SES at the first three assessments, indicating 
Table 1. Means ( \pm S.D.) and proportion (\%) of patient characteristics by level of awareness at each assessment

\begin{tabular}{|c|c|c|c|c|c|c|}
\hline & \multirow{2}{*}{$\begin{array}{l}\text { TOTAI } \\
\text { GROUP }\end{array}$} & \multicolumn{4}{|c|}{ AWARENESS SCORE } & \multirow[b]{2}{*}{$p^{*}$} \\
\hline & & 1 & 2 & 3 & 4 & \\
\hline \multicolumn{7}{|l|}{ Sex (\% male) } \\
\hline Baseline $(n=199)$ & 41.7 & 12.5 & 41.3 & 40.0 & 73.5 & $<0.001$ \\
\hline 6 months $(n=155)$ & 43.2 & 35.3 & 33.9 & 54.5 & 57.1 & 0.08 \\
\hline 1 year $(n=144)$ & 40.3 & 36.4 & 35.6 & 38.5 & 76.9 & 0.05 \\
\hline 18 months $(n=126)$ & 39.7 & 36.6 & 34.0 & 48.3 & 66.7 & 0.31 \\
\hline \multicolumn{7}{|c|}{ Education $(1-8) \dagger$} \\
\hline Baseline & $2.3 \pm 1.7$ & $1.6 \pm 1.2$ & $2.0 \pm 1.4$ & $2.3 \pm 1.8$ & $3.4 \pm 2.2$ & 0.001 \\
\hline 6 months & $2.3 \pm 1.7$ & $2.1 \pm 1.4$ & $1.7 \pm 1.1$ & $2.9 \pm 2.1$ & $3.1 \pm 2.0$ & 0.001 \\
\hline 1 year & $2.3 \pm 1.7$ & $1.9 \pm 1.4$ & $2.0 \pm 1.5$ & $2.7 \pm 1.8$ & $3.7 \pm 2.2$ & 0.006 \\
\hline 18 months & $2.3 \pm 1.6$ & $1.9 \pm 1.3$ & $2.3 \pm 1.7$ & $2.7 \pm 1.7$ & $3.0 \pm 2.0$ & 0.12 \\
\hline \multicolumn{7}{|l|}{$\operatorname{SES}(1-6) \ddagger$} \\
\hline Baseline & $2.1 \pm 1.6$ & $1.5 \pm 1.2$ & $2.0 \pm 1.6$ & $2.1 \pm 1.4$ & $3.1 \pm 1.9$ & $<0.001$ \\
\hline 6 months & $3.1 \pm 1.9$ & $1.8 \pm 1.3$ & $1.6 \pm 1.1$ & $2.7 \pm 1.8$ & $3.1 \pm 1.9$ & $<0.001$ \\
\hline 1 year & $2.2 \pm 1.6$ & $1.8 \pm 1.3$ & $1.8 \pm 1.4$ & $2.7 \pm 1.8$ & $3.4 \pm 1.8$ & $<0.001$ \\
\hline 18 months & $2.2 \pm 1.6$ & $1.8 \pm 1.4$ & $2.2 \pm 1.6$ & $2.5 \pm 1.7$ & $2.7 \pm 1.9$ & 0.10 \\
\hline \multicolumn{7}{|l|}{ Age } \\
\hline Baseline & $76.4 \pm 8.0$ & $79.3 \pm 8.8$ & $77.2 \pm 7.0$ & $75.3 \pm 7.8$ & $74.6 \pm 8.7$ & 0.05 \\
\hline 6 months & $76.7 \pm 8.1$ & $78.6 \pm 7.5$ & $77.3 \pm 8.1$ & $76.1 \pm 8.0$ & $73.6 \pm 9.0$ & 0.15 \\
\hline 1 year & $77.2 \pm 8.1$ & $79.1 \pm 7.5$ & $77.1 \pm 8.6$ & $77.9 \pm 7.6$ & 71.2 上 7.3 & 0.03 \\
\hline 18 months & $77.4 \pm 8.0$ & $78.4 \pm 7.0$ & $78.3 \pm 8.1$ & $75.9 \pm 9.1$ & $71.3 \pm 5.4$ & 0.12 \\
\hline \multicolumn{7}{|c|}{ 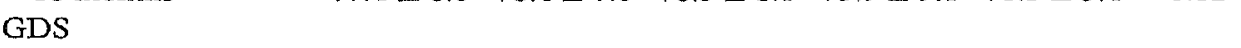 } \\
\hline Baseline & $4.1 \pm 0.7$ & $4.6 \pm 0.7$ & $4.2 \pm 0.7$ & $4.0 \pm 0.6$ & $3.8 \pm 0.7$ & $<0.001$ \\
\hline 6 months & $4.6 \pm 0.8$ & $5.0 \pm 0.8$ & $4.7 \pm 0.8$ & $4.3 \pm 0.7$ & $4.1 \pm 0.6$ & $<0.001$ \\
\hline 1 year & $4.7 \pm 0.7$ & $5.2 \pm 0.6$ & $4.6 \pm 0.6$ & $4.7 \pm 0.6$ & $4.2 \pm 0.7$ & $<0.001$ \\
\hline 18 months & $4.9 \pm 0.7$ & $5.2 \pm 0.6$ & $4.9 \pm 0.6$ & $4.6 \pm 0.7$ & $4.3 \pm 0.5$ & $<0.001$ \\
\hline \multicolumn{7}{|l|}{ MMSE } \\
\hline Baseline $(n=193)$ & $18.1 \pm 4.7$ & $17.2 \pm 4.4$ & $17.2 \pm 5.0$ & $18.0 \pm 4.1$ & $20.6 \pm 4.9$ & 0.01 \\
\hline 6 months $(n=147)$ & $17.1 \pm 5.4$ & $14.0 \pm 5.6$ & $16.4 \pm 4.1$ & $18.9 \pm 5.2$ & $20.2 \pm 5.5$ & $<0.001$ \\
\hline 1 year $(n=118)$ & $16.1 \pm 5.8$ & $14.0 \pm 5.7$ & $15.5 \pm 5.2$ & $16.5 \pm 6.3$ & $20.5 \pm 4.7$ & 0.01 \\
\hline 18 months $(n=98)$ & $16.0 \pm 6.1$ & $13.6 \pm 5.7$ & $15.6 \pm 6.4$ & $19.0 \pm 5.3$ & $18.6 \pm 3.7$ & 0.01 \\
\hline \multicolumn{7}{|l|}{ Disease duration } \\
\hline Baseline $(n=187)$ & $3.0 \pm 2.2$ & $3.0 \pm 2.5$ & $3.0 \pm 2.2$ & $3.1 \pm 2.1$ & $3.0 \pm 2.0$ & 0.995 \\
\hline 6 months $(n=147)$ & $3.6 \pm 2.2$ & $3.5 \pm 2.6$ & $3.6 \pm 2.1$ & $3.6 \pm 2.2$ & $3.4 \pm 2.0$ & 0.979 \\
\hline 1 year $(n=135)$ & $4.0 \pm 2.2$ & $4.6 \pm 3.0$ & $3.8 \pm 1.8$ & $4.0 \pm 2.2$ & $4.0 \pm 2.3$ & 0.46 \\
\hline 18 months $(n=118)$ & $4.5 \pm 2.2$ & $4.7 \pm 2.7$ & $4.6 \pm 1.9$ & $4.4 \pm 2.2$ & $3.6 \pm 1.1$ & 0.67 \\
\hline
\end{tabular}

SES = socioeconomic status; $G D S=$ Global Deterioration Scale; MMSE $=$ Mini-mental State Examination.

* Based on one-way ANOVA, $\chi^{2}$ analysis was used for sex and the Kruskal-Wallis test for education and SES.

$\dagger$ Ranging from primary education to university degree.

$\ddagger$ Ranging from untrained work to higher profession. 
Table 2. Cross-sectional analysis; associations between levels of awareness and behavioral disorders at baseline and after 1 year

\begin{tabular}{|c|c|c|c|c|c|c|}
\hline & \multicolumn{3}{|c|}{ BASELINE $\quad(n=199)$} & \multicolumn{3}{|c|}{1 YEAR $(n=144)$} \\
\hline & OR & $p$ & $95 \%$ C I & OR & $p$ & $95 \% \quad$ CI \\
\hline Mood/apathy & 0.84 & 0.32 & $0.60-1.18$ & 1.21 & 0.39 & $0.79-1.84$ \\
\hline Hyperactivity & 0.78 & 0.15 & $0.55-1.10$ & 1.05 & 0.84 & $0.68-1.60$ \\
\hline Psychosis & 0.66 & 0.03 & $0.46-0.95$ & 0.85 & 0.46 & $0.56-1.30$ \\
\hline Anxiety & 0.99 & 0.97 & $0.71-1.40$ & 1.95 & 0.01 & $1.23-3.08$ \\
\hline Depression & 1.24 & 0.22 & $0.88-1.76$ & 1.63 & 0.03 & $1.05-2.55$ \\
\hline Apathy & 0.61 & 0.01 & $0.43-0.86$ & 0.98 & 0.94 & $0.64-1.50$ \\
\hline NPI total & 0.61 & 0.01 & $0.43-0.87$ & 1.17 & 0.49 & $0.76-1.79$ \\
\hline CSDD & 1.13 & 0.49 & $0.80-1.58$ & 1.15 & 0.51 & $0.76-1.75$ \\
\hline
\end{tabular}

$\mathrm{OR}=$ odds ratio; $95 \% \mathrm{CI}=95 \%$ confidence interval; NPI $=$ Neuropsychiatric Inventory; $\mathrm{CSDD}=$ Cornell Scale for Depression in Dementia.

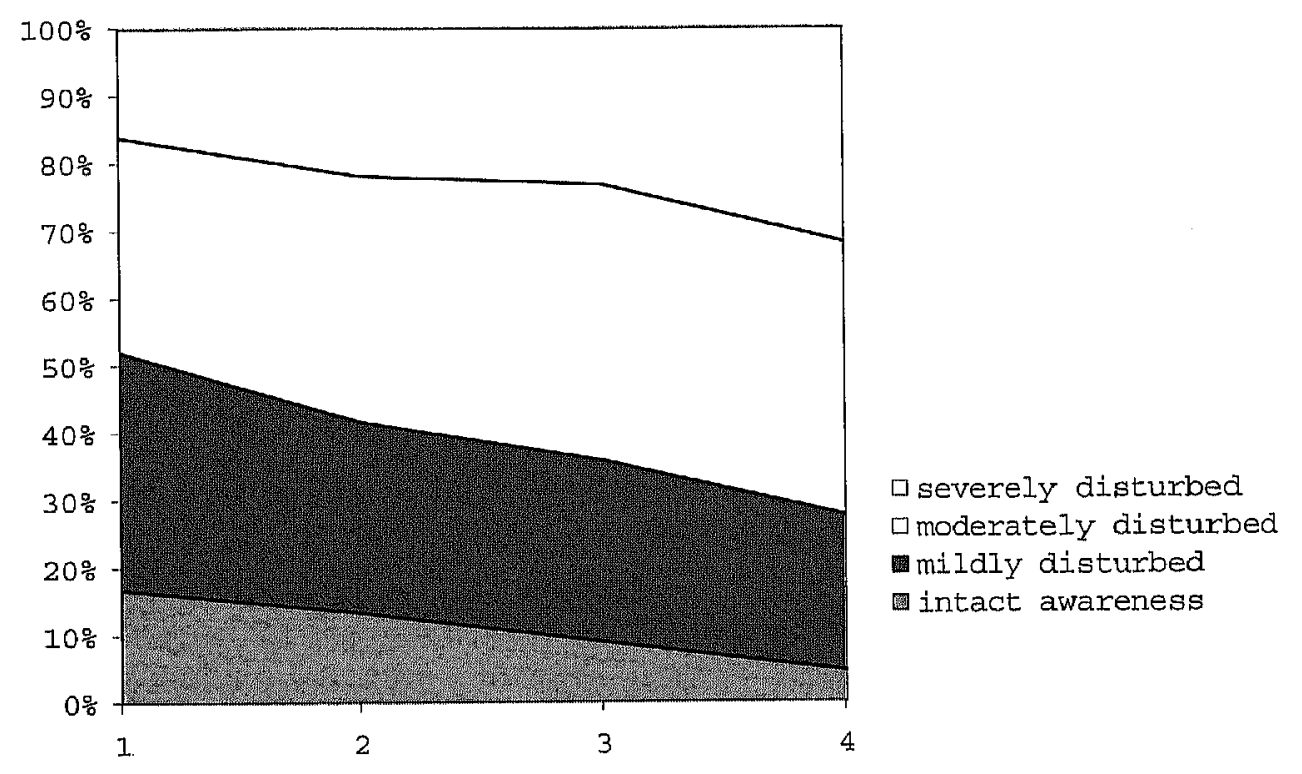

Fig. 1. Relative proportional distribution of GRAD scores

higher levels of awareness in patients with higher education levels and higher SES. Disease duration was not associated with the level of awareness.

\section{Awareness and behavioral disorders}

CROSS-SECTIONAL ANALYSES

Logistic regression analyses were performed to determine whether awareness and behavioral disorders were associated (Table 2). At baseline, low levels of awareness were associated with psychosis [odds ratio $(\mathrm{OR})=0.66 ; p=0.03 ; 95 \%$ 
Table 3. Distribution of awareness scores across assessments and changes from baseline

\begin{tabular}{|c|c|c|c|c|c|}
\hline & & $\begin{array}{l}\text { ANGE IN } \\
\text { RES FRC }\end{array}$ & $\begin{array}{l}\text { AWAREN } \\
\text { M BASEL }\end{array}$ & & DISTRIBUTION \\
\hline & 1 & 2 & 3 & 4 & ASSES SMENT \\
\hline Baseline & & & & & \\
\hline GRAD1 & & & & & $32(16.1)$ \\
\hline GRAD 2 & & & & & $63(31.7)$ \\
\hline GRAD 3 & & & & & $70(35.2)$ \\
\hline GRAD 4 & & & & & $34(17.1)$ \\
\hline Total $n$ & & After & & & 199 \\
\hline 6 months & & & & & \\
\hline GRAD 1 & $18(69.2)$ & $11(25.0)$ & $5(9.3)$ & 0 & $34(21.9)$ \\
\hline GRAD 2 & $6(23.1)$ & $28(63.6)$ & $21(38.9)$ & $1(3.2)$ & $56(36.1)$ \\
\hline GRAD 3 & $1(3.8)$ & $4(9.1)$ & $24(44.4)$ & $15(48.4)$ & $44(28.4)$ \\
\hline GRAD 4 & $1(3.8)$ & $1(2.3)$ & $4(7.4)$ & $15(48.4)$ & $21(13.5)$ \\
\hline Total $n$ & 26 & 44 & 54 & 31 & 155 \\
\hline 1 year & & & & & \\
\hline GRAD 1 & $13(61.9)$ & $12(25.0)$ & $8(16.0)$ & 0 & $33(22.9)$ \\
\hline GRAD 2 & $6(28.6)$ & $33(68.8)$ & $17(34.0)$ & $3(12.0)$ & $59(41.0)$ \\
\hline GRAD 3 & $2(9.5)$ & $3(6.3)$ & $21(42.0)$ & $13(52.0)$ & $39(27.1)$ \\
\hline GRAD 4 & 0 & 0 & $4(8.0)$ & $9(36.0)$ & $13(9.0)$ \\
\hline Total $n$ & 21 & 48 & 50 & 25 & 144 \\
\hline 18 months & & & & & \\
\hline GRAD 1 & $15(75.0)$ & $17(39.5)$ & $8(18.6)$ & 0 & $40(31.7)$ \\
\hline GRAD 2 & $4(20.0)$ & $23(53.5)$ & $18(41.9)$ & $6(30.0)$ & $51(40.5)$ \\
\hline GRAD 3 & $1(5.0)$ & $3(7.0)$ & $15(34.9)$ & $10(50.0)$ & $29(23.0)$ \\
\hline GRAD 4 & 0 & 0 & $2(4.7)$ & $4(20)$ & $6(4.8)$ \\
\hline Total $n$ & 20 & 43 & 43 & 20 & 126 \\
\hline
\end{tabular}

Values are given as $n(\%)$.

Awareness scores: $1=$ severely disturbed; $2=$ moderately disturbed; $3=$ mildly disturbed; $4=$ intact. GRAD $=$ Guidelines for the Rating of Awareness Deficits.

confidence interval $(95 \% \mathrm{CI})=0.46-0.95]$ and apathy $(\mathrm{OR}=0.61 ; p=0.01$; $95 \% \mathrm{CI}=0.43-0.86)$, and a higher NPI total score (OR $=0.61 ; p=0.01 ; 95 \%$ $\mathrm{CI}=0.43-0.87)$. There were no significant associations at 6 months. After 1 year, awareness was positively related to anxiety (OR $=1.95 ; p=0.01 ; 95 \%$ $\mathrm{CI}=1.23-3.08)$ and depression $(\mathrm{OR}=1.63 ; p=0.03 ; 95 \% \mathrm{CI}=1.05-2.55)$. The subsyndromes mood/apathy and hyperactivity were not associated with level of awareness, and neither was awareness nor the CSDD score.

AWARENESS AS PREDICTOR OF BEHAVIORAL

AND PSYCHOLOGICAL SYMPTOMS

The baseline level of awareness was positively associated with anxiety after 1 year $(\mathrm{OR}=1.76 ; p=0.01 ; 95 \% \mathrm{CI}=1.13-2.76)$ and 18 months $(\mathrm{OR}=1.85$; 
$p=0.02 ; 95 \% \mathrm{CI}=1.13-3.02)$. At 1 year, intact awareness at baseline was also associated with greater depression ( $\mathrm{OR}=1.55 ; p=0.05 ; 95 \% \mathrm{CI}=1.00-2.39$ ). No other longitudinal relationships were found between baseline awareness and other behavioral disorders.

\section{Course of awareness}

ANOVA with repeated measures showed a significant time effect $(F(3,348)=$ 23.81, $p<0.001$ ), indicating that the level of awareness decreased significantly during the follow-up. At baseline, 34 of 199 patients (17.1\%) had an intact awareness, and 70 patients $(35.2 \%)$ had a mildly disturbed awareness, so at baseline around $50 \%$ of the patients had intact or mildly disturbed awareness (see Figure 1 and Table 3). At the 18-month follow-up the awareness of most patients with either mild or intact awareness had decreased, whereas that of most patients with severely disturbed awareness remained stable. Around just a fifth of patients with intact awareness at baseline continued to have this 18 months later. Awareness improved in three patients at subsequent assessments from severely disturbed to mildly disturbed or intact awareness. Changes in medication use in these patients were not responsible for this improvement of awareness.

\section{Discussion}

The main question of this study was whether awareness was related to behavioral problems in patients with dementia. We found that high levels of awareness at baseline were predictive for anxiety at 12 and 18 months, and depression at 12 months. These associations were also found at 12 months, cross-sectional. Starkstein et al. (1997) and Derouesné et al. (1999) found awareness to be a predictor of the emergence of depression and "emotional deficit" (including anxiety symptoms), after a mean interval of 16 and 21 months, respectively. Combined, the studies suggest that awareness is a predictor for depressive symptoms and anxiety. Other authors, in cross-sectional studies, have found depression to be more common among patients with higher levels of awareness (Burke et al., 1998; Feher et al., 1991; Harwood et al., 2000; Migliorelli et al., 1995; Seltzer et al., 1995; Sevush and Leve, 1993; Smith et al., 2000; Starkstein et al., 1996; 1997), whereas others have not (Arkin and Mahendra, 2001; Cummings et al., 1995; DeBettignies et al., 1990; Derouesné et al., 1999; Lopez et al., 1994; Michon et al., 1994; Ott et al., 1996a; Reed et al., 1993; Verhey et al., 1993; Zanetti et al., 1999). Some authors found that less severe forms of depression, such as dysthymia, were associated with greater awareness (Migliorelli et al., 1995; Starkstein et al., 1997) and suggested that dysthymia represented an emotional response to progressive cognitive decline, whereas 
major depression was associated with a biological etiology unrelated to awareness. A recent review indicated that awareness is only related to subsyndromal depression (Aalten et al., 2005). Further studies should address this issue. A positive association between awareness and anxiety has been reported less often (Derouesné et al., 1999; Harwood et al., 2000; Verhey et al., 1993). Like depression, feelings of anxiety may be the result of a psychological reaction to painful insight into cognitive decline.

The negative association between psychosis and awareness we found in this study has been reported previously (Mangone et al., 1991; Migliorelli et al., 1995; Starkstein et al., 1996; 1997) and may be explained from a psychopathological perspective. Because of impaired reality testing abilities related to cognitive decline, patients with low levels of awareness might be less able to recognize changes in themselves or in their environment. As a result, they may compensate for this by incorrect rationalizations resulting in psychosis. An alternative explanation is that both awareness and psychosis are related to dysfunction of certain brain structures or systems that are themselves variably affected by the progression of dementia.

We, like others (Derouesné et al., 1999; Robert et al., 2002; Starkstein et al., $1996 ; 2001)$, found awareness to be negatively associated with apathy at baseline. Patients who are unaware of their deficits may be less reactive to their environment and to their needs and emotions, resulting in apathy. Loss of awareness, as well as psychosis and apathy, has been related to neuropathological changes in right frontal and related subcortical structures (Mega et al., 2000; Migliorelli et al., 1995; Ott et al., 1996b; Reed et al., 1993). The shared neuropathological substrates may be the reason why fewer inconsistencies are reported between studies assessing these relationships in early stages of dementia.

Awareness did not, however, seem to be predictive for the subsyndrome mood/apathy and the CSDD. This may be because the NPI subsyndrome and the CSDD include both apathy and depression, which have opposite relationships to awareness. In addition, like the symptom depression, in our study both mood/apathy and the CSDD did not specifically measure dysthymia.

Previous studies have found higher levels of unawareness to be associated with agitation (Harwood et al., 2000) and irritability (Seltzer et al., 1995), which are symptoms included in our "hyperactivity" subsyndrome. Subanalyses (not reported here) found negative associations between awareness and agitation at baseline and after 6 months. Although some authors suggest that lack of awareness is greater in patients with Alzheimer's disease than in those with dementia of other etiologies (DeBettignies et al., 1990; Wagner et al., 1997), we and others (Verhey et al., 1995; Zanetti et al., 1999) found no evidence for this.

We also investigated whether the level of awareness is associated with major demographic variables and how awareness changes during the course of 
dementia. We found that higher levels of awareness were associated with younger age, mild/moderate severity of dementia, male sex, and higher education and SES level. Most studies have not found awareness to be associated with age (Arkin and Mahendra, 2001; DeBettignies et al., 1990; Feher et al., 1991; Harwood et al., 2000; Lopez et al., 1994; Reed et al., 1993; Sevush and Leve, 1993; Starkstein et al., 1997; Vasterling et al., 1995; 1997), although some have (Derouesné et al., 1999). The association with male sex was also found by Sevush and Leve (1993). Our finding that a preserved awareness was associated with more intact cognitive functioning, as measured with the MMSE and GDS, supports previous research (Derouesné et al., 1999; Feher et al., 1991; Harwood et al., 2000; Lopez et al., 1994; Mangone et al., 1991; Migliorelli et al., 1995; Seltzer et al., 1995; Sevush, 1999; Sevush and Leve, 1993; Starkstein et al., 1996; 1997; Vasterling et al., 1995; Verhey et al., 1993; Zanetti et al., 1999). To our knowledge, this study is the first to show awareness to be associated with education and SES. Patients with higher educational and occupational backgrounds may have more knowledge regarding characteristics and impact of dementia, and are therefore better able to perceive and interpret their own cognitive deterioration. We did not find duration of illness to be associated with level of awareness, in line with most other studies (Derouesné et al., 1999; Mangone et al., 1991; Reed et al., 1993; Sevush and Leve, 1993; Vasterling et al., 1995; 1997).

Impaired awareness was common and, at baseline, $82.9 \%$ of the patients in our study had some degree of impaired awareness, as found by others (Derouesné et al., 1999; Reed et al., 1993; Sevush, 1999; Verhey et al., 1993). Awareness decreased with time in most patients with either mild or intact awareness at baseline, whereas it tended to be stable in most patients with more severe limitations of awareness at baseline. Three patients showed an improvement in awareness at subsequent assessments, as found by other researchers (Arkin and Mahendra, 2001; Derouesné et al., 1999). This supports the view that awareness is not simply a symptom of a disease that becomes progressively more severe and suggests that psychological and social factors contribute to the manifestation of disturbed awareness (Clare, 2004a).

Although the results of this study were in some respects ambiguous, taken together with previous studies our findings suggest that a relatively intact awareness is associated with subsyndromal depression and anxiety, and that lower levels of awareness are related to psychosis and apathy. The strengths of the present study are its prospective design, the use of a structured instrument for assessing behavioral problems, and the inclusion of a representative clinical sample that is larger than in previous studies. The discrepancies between our and other studies may be attributed, at least in part, to differences in theoretical and conceptual formulations and methods of measuring awareness and behavioral 
problems. In addition, a weakness of our study is the use of the four-point rating scale of the GRAD, which may be too general to assess a complex phenomenon such as awareness. However, the use of a clinician rating method has the advantage of allowing a rapid assessment of awareness, and assessing awareness in the context of an interview might allow for comprehension to be checked and answers to be explored in more detail. Nevertheless, it is important for future work to focus on developing better conceptual frameworks and methodological approaches of awareness that are of use to clinicians and can contribute to enhancing the quality of care for people with dementia and their families (Aalten et al., 2005; Clare, 2004a; Clare et al., 2005).

Our findings can help clinicians to determine which of their patients are at risk of developing depression or anxiety. Clinicians should be more alert to changes in awareness in patients with dementia, and often psychological support is of importance as it may help to reduce depression and anxiety in patients with an intact awareness. Other studies are needed to investigate whether psychological approaches to depression and anxiety are effective, with emphasis on biological interventions for the treatment of major depression, psychosis and apathy.

\section{Conflict of interest}

None.

\section{Description of author's roles}

Both Frans Verhey and Jelle Jolles had a role in formulating the research question, designing the study and writing the article. Pauline Aalten was the main researcher and psychologist of this study, and, along with Marjolein de Vugt, participated in formulating the research question, designing the study, carrying it out, analyzing the data and writing the article. Evelien van Valen collected the data and assisted with writing the article. Richel Lousberg helped with the statistical analyses of the study.

\section{Acknowledgments}

This study was funded by the Dutch Research Council (NWO: 940-33-039).

\section{References}

Aalten, P. et al. (2003). Behavioral problems in dementia: a factor analysis of the neuropsychiatric inventory. Dementia and Geriatric Cognitive Disorders, 15, 99-105. 
Aalten, P., Van Valen, E., Clare, L., Kenny, G. and Verhey, F. (2005). Awareness in dementia: a review of clinical correlates. Aging and Mental Health, 9, 414-422.

Alexopoulos, G. S., Abrams, R. C., Young, R. C. and Shamoian, C. A. (1988). Cornell Scale for Depression in Dementia. Biological Psychiatry, 23, 271-284.

American Psychiatric Association (1994). Diagnostic and Statistical Manulal of Mental Disorders: DSM-IV (4th ed.). Washington, D.C.: American Psychiatric Association.

Arkin, S. and Mahendra, N. (2001). Insight in Alzheimer's patients: results of a longitudinal study using three assessment methods. American fournal of Alzheimer's Disease and Other Dementias, 16, 211-224.

Auchus, A. P., Goldstein, F. C., Green, J. and Green, R. C. (1994). Unawareness of cognitive impairments in Alzheimer's disease. Neuropsychiatry, Neuropsychology, and Behavioral Neurology, 7, 25-29.

Burke, W. J., Roccaforte, W. H., Wengel, S. P., McArthur-Miller, D., Folks, D. G. and Potter, J. F. (1998). Disagreement in the reporting of depressive symptoms between patients with dementia of the Alzheimer type and their collateral sources. American Fournal of Geriatric Psychiatry, 6, 308-319.

Clare, L. (2004a). Awareness in early-stage Alzheimer's disease: a review of methods and evidence. British Foumal of Clinical Psychology, 43, 177-196.

Clare, L. (2004b). The construction of awareness in early-stage Alzheimer's disease: a review of concepts and models. British fournal of Clinical Psychology, 43, 155-175.

Clare, L., Markova, I., Verhey, F. and Kenny, G. (2005). Awareness in dementia: a review of assessment methods and measures. Aging and Mental Health, 9, 394-413.

Cummings, J. L. (1997). The Neuropsychiatric Inventory: assessing psychopathology in dementia patients. Neurology, 48, S10-S16.

Cummings, J. L. and McPherson, S. (2001). Neuropsychiatric assessment of Alzheimer's disease and related dementias. Aging (Milano), 13, 240-246.

Cummings, J. L., Mega, M., Gray, K., Rosenberg-Thompson, S., Carusi, D. A. and Gornbein, J. (1994). The Neuropsychiatric Inventory: comprehensive assessment of psychopathology in dementia. Neurology, 44, 2308-2314.

Cummings, J. L., Ross, W., Absher, J., Gornbein, J. and Hadjiaghai, L. (1995). Depressive symptoms in Alzheimer disease: assessment and determinants, Alzheimer Disease and Associated Disorders, 9, 87-93.

DeBettignies, B. H., Mahurin, R. K. and Pirozzolo, F. J. (1990). Insight for impairment in independent living skills in Alzheimer's disease and multi-infarct dementia, Fournal of Clinical Experience and Neuropsychology, 12, 355-363.

Derouesné, C., Thibault, S., Lagha-Pierucci, S., Baudouin-Madec, V., Ancri, D. and Lacomblez, L. (1999). Decreased awareness of cognitive deficits in patients with mild dementia of the Alzheimer type. International fournal of Geriatric Psychiatry, 14, 1019-1030.

Feher, E. P., Mahurin, R. K., Inbody, S. B., Crook, T. H. and Pirozzolo, F. J. (1991). Anosognosia in Alzheimer's disease. Neuropsychiatry, Neuropsychology, and Behavioral Neurology, 4, 136-146.

Folstein, M. F., Folstein, S. E. and McHugh, P. R. (1975). "Mini-mental state". A practical method for grading the cognitive state of patients for the clinician. Fournal of Psychiatric Research, 12, 189-198.

Harwood, D. G., Sultzer, D. L. and Wheatley, M. V. (2000). Impaired insight in Alzheimer disease: association with cognitive deficits, psychiatric symptoms and behavioral disturbances. Neuropsychiatry, Neuropsychology, and Behavioral Neurology, 13, 83-88.

Kat, M. G., de Jonghe, J. F., Aalten, P., Kalisvaart, C. J., Droes, R. M. and Verhey, F. R. (2002). Neuropsychiatric symptoms of dementia: psychometric aspects of the Dutch Neuropsychiatric Inventory (NPI)]. Tijdschrift voor Gerontologie en Geriatrie, 33, 150155. 
Kotler-Cope, S. and Camp, C. J. (1995). Anosognosia in Alzheimer disease. Alzheimer Disease and Associated Disorders, 9, 52-56.

Lopez, O. L., Becker, J. T., Sonsak, D., Dew, M. A. and DeKosky, S. T. (1994). Awareness of cognitive deficits and anosognosia in probable Alzheimer's disease. European Neurology, 34, $277-282$.

Mangone, C. A. et al. (1991). Impaired insight in Alzheimer's disease. fournal of Geriatric Psychiatry and Neurology, 4, 189-193.

Markova, I. S., Clare, L., Wang, M., Romero, B. and Kenny, G. (2005). Awareness in dementia: conceptual issues. Aging and Mental Health, 9, 386-393.

McKeith, I. G. et al. (1996). Consensus guidelines for the clinical and pathologic diagnosis of dementia with Lewy bodies (DLB): report of the consortium on DLB international workshop. Neurology, 47, 1113-1124.

McKhann, G., Drachman, D., Folstein, M., Katzman, R., Price, D. and Stadlan, E. M. (1984). Clinical diagnosis of Alzheimer's disease: report of the NINCDS-ADRDA Work Group under the auspices of Department of Health and Human Services Task Force on Alzheimer's Disease. Neurology, 34, 939-944.

Mega, M. S., Lee, L., Dinov, I. D., Mishkin, F., Toga, A. W. and Cummings, J. L. (2000). Cerebral correlates of psychotic symptoms in Alzheimer's disease. Fournal of Neutology, Neurosurgery and Psychiatry, 69, 167-171.

Michon, A., Deweer, B., Pillon, B., Agid, Y. and Dubois, B. (1994). Relation of anosognosia to frontal lobe dysfunction in Alzheimer's disease. Fournal of Neurology, Neurosurgery, and Psychiatry, 57, 805-809.

Migliorelli, R. et al. (1995). Anosognosia in Alzheimer's disease: a study of associated factors. Fournal of Neuropsychiatry and Clinical Neuroscience, 7, 338-344.

Ott, B. R., Lafleche, G., Whelihan, W. M., Buongiorno, G. W., Albert, M. S. and Fogel, B. S. (1996a), Impaired awareness of deficits in Alzheimer disease. Alzheimer Disease and Associated Disorders, 10, 68-76.

Ott, B. R., Noto, R. B. and Fogel, B. S. (1996b). Apathy and loss of insight in Alzheimer's disease: a SPECT imaging study. Foumnal of Neuropsychiatry and Clinical Neurosciences, 8 , $41-46$.

Reed, B. R., Jagust, W. J. and Coulter, L. (1993). Anosognosia in Alzheimer's disease: relationships to depression, cognitive function and cerebral perfusion. Fournal of Clinical Experience and Neuropsychology, 15, 231-244.

Reisberg, B., Ferris, S. H., de Leon, M. J. and Crook, T. (1982). The Global Deterioration Scale for assessment of primary degenerative dementia. American foumal of Psychiatry, 139, 1136-1139.

Robert, P. H. et al. (2002). The apathy inventory: assessment of apathy and awareness in Alzheimer's disease, Parkinson's disease and mild cognitive impairment. International foumnal of Geriatric Psychiatry, 17, 1099-1 105.

Román, G. C. et al. (1993). Vascular dementia: diagnostic criteria for research studies. Report of the NINDS-AIREN International Workshop. Neurology, 43, 250-260.

Seltzer, B., Vasterling, J. J., Hale, M. A. and Khurana, R. (1995). Unawareness of memory deficit in Alzheimer's disease: relation to mood and other disease variables. Neuropsychiatry, Neuropsychology, and Behavioral Neurology, 8, 176-181.

Sevush, S. (1999). Relationship between denial of memory deficit and dementia severity in Alzheimer disease. Neuropsychiatry, Neuropsychology, and Behavional Neurology, 12, 88-94.

Sevush, S. and Leve, N. (1993). Denial of memory deficit in Alzheimer's disease. American Foumal of Psychiat'y, 150, 748-751.

Smith, C. A., Henderson, V. W., McCleary, C. A., Murdock, G. A. and Buckwalter, J. G. (2000). Anosognosia and Alzheimer's disease: the role of depressive symptoms in mediating impaired insight. Fournal of Clinical Experience and Neuropsychology, 22, 437-444. 
Starkstein, S. E. et al. (1995). The prevalence and clinical correlates of apathy and irritability in Alzheimer's disease. European fournal of Neurology, 2, 540-546.

Starkstein, S. E., Sabe, L., Chemerinski, E., Jason, L. and Leiguarda, R. (1996). Two domains of anosognosia in Alzheimer's disease. Fournal of Neurology, Neurosurgery, and Psychiatry, 61, 485-490.

Starkstein, S. E. et al. (1997). Prospective longitudinal study of depression and anosognosia in Alzheimer's disease. British Foumnal of Psychiatry, 171, 47-52.

Starkstein, S. E., Petracca, G., Chemerinski, E. and Kremer, J. (2001). Syndromic validity of apathy in Alzheimer's disease. Anerican fournal of Psychiatry, 158, 872-877.

Vasterling, J. J., Seltzer, B., Foss, J. W. and Vanderbrook, V. (1995). Unawareness of deficit in Alzheimer's disease. Neuropsychiatry, Neuropsychology, and Behavioral Neurology, 8, 26-32.

Vasterling, J. J., Seltzer, B. and Watrous, W. E. (1997). Longitudinal assessment of deficit unawareness in Alzheimer's disease, Neuropsychiatry, Neuropsychology, and Behavioral Neurology, 10, 197-202.

Verhey, F. R. J., Rozendaal, N., Ponds, R. W. H. M. and Jolles, J. (1993). Dementia, awareness and depression. International fournal of Geriatric Psychiatry, 8, 851-856.

Verhey, F. R., Ponds, R. W., Rozendaal, N. and Jolles, J. (1995). Depression, insight and personality changes in Alzheimer's disease and vascular dementia. Fournal of Geriatric Psychiatry and Neurology, 8, 23-27,

Wagner, M. T., Spangenberg, K. B., Bachman, D. L. and O'Connell, P. (1997). Unawareness of cognitive deficit in Alzheimer disease and related dementias. Alzheimer Disease and Associated Disorders, 11, 125-131.

Zanetti, O. et al. (1999). Insight in dementia: when does it occur? Evidence for a nonlinear relationship between insight and cognitive status. Fournal of Gerontology: Psychological Sciences, $54,100-106$. 